\title{
Impacts of Operation of CVP Regulating Reservoirs on Water Temperature
}

\author{
L. W. Vail
}

June 1996

Prepared for the

Western Area Power Administration under a Related Services Agreement with the U.S. Department of Energy

Contract DE-AC06-76RLO 1830

Pacific Northwest National Laboratory

Richland, Washington 99352

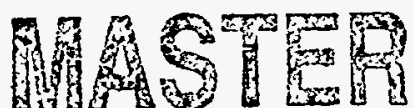

DLSTRIBUTION OF THIS DOCUMENT IS URLRMTED h 


\section{DISCLAIMER}

Portions of this document may be illegible in electronic image products. Images are produced from the best available original document. 


\title{
DISCLAIMER
}

This report was prepared as an account of work sponsored by an agency of the United States Government. Neither the United States Government nor any agency thereof, nor Battelle Memorial Institute, nor any of their employees, makes any warranty, express or implied, or assumes any legal liability or responsibility for the accuracy, completeness, or usefulness of any information, apparatus, product, or process disclosed, or represents that its use would not infringe privately owned rights. Reference herein to any specific commercial product, process, or service by trade name, trademark, manufacturer, or otherwise does not necessarily constitute or imply its endorsement, recommendation, or favoring by the United States Government or any agency thereof, or Battelle Memorial Institute. The views and opinions of authors expressed herein do not necessarily state or reflect those of the United States Government or any agency thereof.

\author{
PACIFIC NORTHWEST NATIONAL LABORATORY \\ operated by \\ BATTELLE \\ for the \\ UNITED STATES DEPARTMENT OF ENERGY \\ under Contract DE-ACO6-76RLO 1830
}

Printed in the United States of America

Available to DOE and DOE contractors from the

Office of Scientific and Technical Information, P.O. Box 62, Oak Ridge, TN 37831;

prices available from (615) 576-8401.

Available to the public from the National Technical Information Service,

U.S. Department of Commerce, 5285 Port Royal Rd., Springfield, VA 22161 


\section{Summary}

The Western Area Power Administration's Sierra Nevada Customer Service Region (Sierra Nevada Region) markets power from the Central Valley Project. Existing contracts for the sale of the Sierra Nevada Region's resourcès expire in the year 2004. Determining levels of long-term power resources to be marketed and subsequently entering into contracts for the delivery of related products and services could be a major Federal action with potentially significant impacts to the environment. Consequently, a 2004 Power Marketing Environmental Impact Statement (2004 EIS) is being prepared (Western 1996). Three reservoir operating alternatives (no action, maximize hydropower peaking, and maximize hydropower baseload) were designed to encompass the range of reasonable options; thus, the analyses of their environmental effects would bracket the range of potential impacts.

Water temperature and water flow rates have been identified as critical parameters in the habitat suitability for many fish, including some species listed as threatened or endangered. However, the flow rates below the regulating reservoirs are the same for all alternatives. Therefore, the assessment of impacts from water changes was limited to temperature changes that may' occur downstream of the regulating reservoirs based on the differences in the three alternatives.

Because of the unique conditions of the regulating reservoirs (generally well mixed with short residence times), the development of a specific reservoir thermal model was required. This model considers all of the important surface heat exchange processes on an hourly basis. The predictive reliability of the model is limited by the lack of site-specific climate data and, in certain situations, the assumption of unstratified flow. However, the model is useful for estimating the magnitude of the change in release temperatures between the various alternatives.

Based on the model results, no significant changes in water temperatures were detected between the three alternatives. 


\section{Contents}

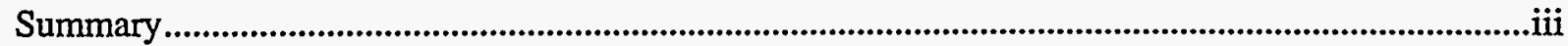

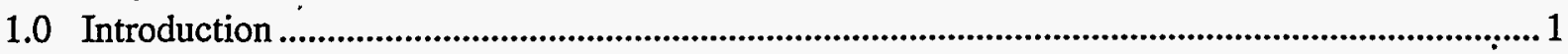

2.0 Geography and Topography of the Central Valley Project................................................................3

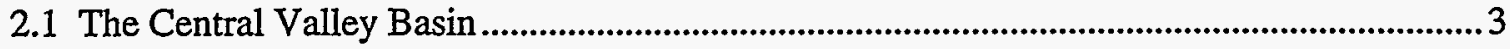

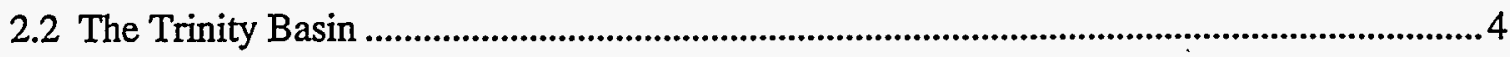

3.0 Hydrosystem of the Central Valley Project ..................................................................................

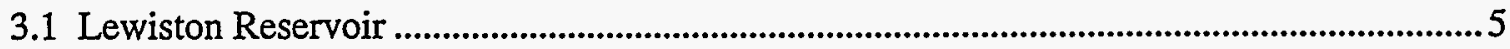

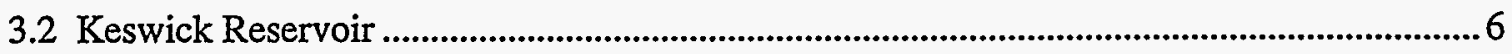

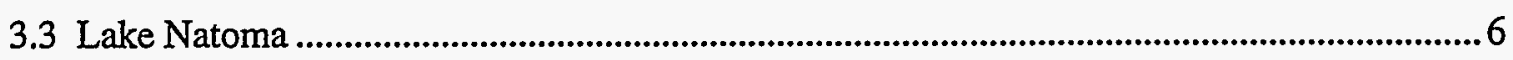

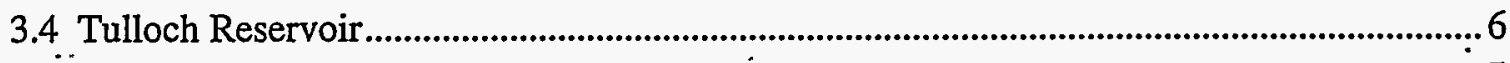

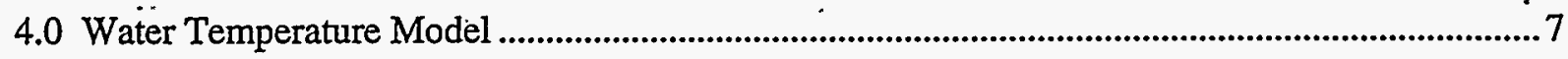

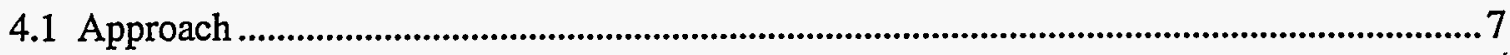

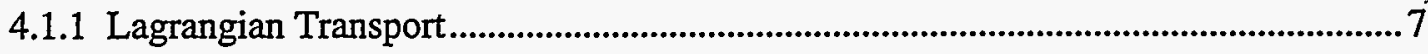

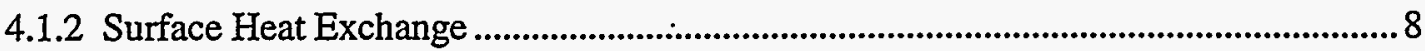

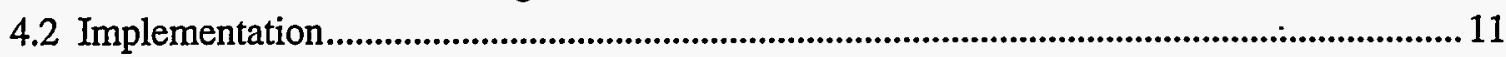

4.3 Input

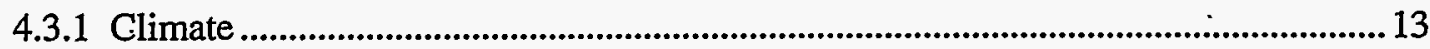

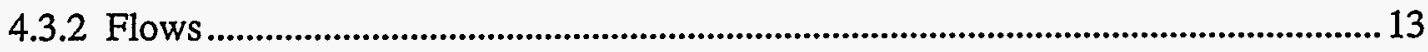

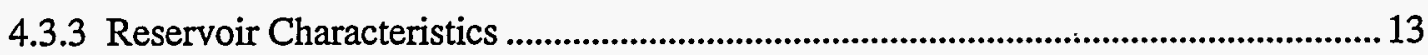

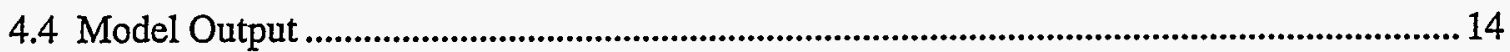

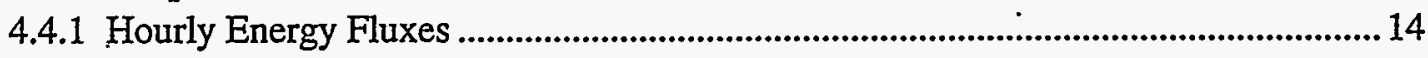



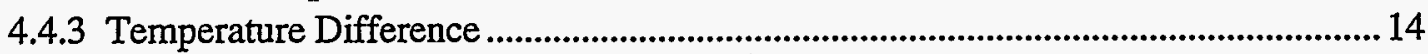

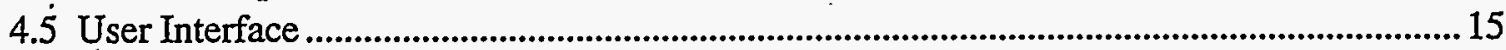

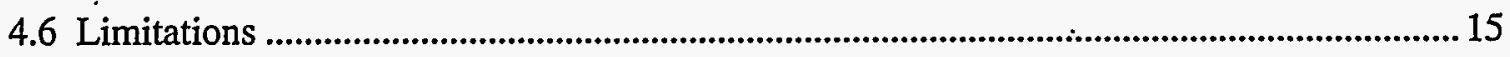

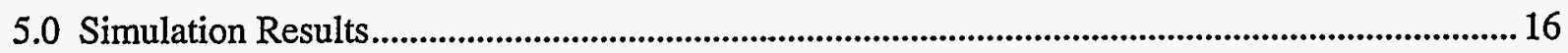

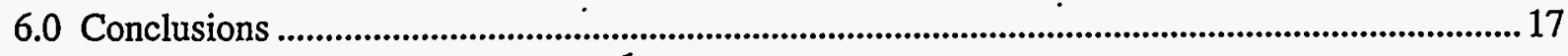

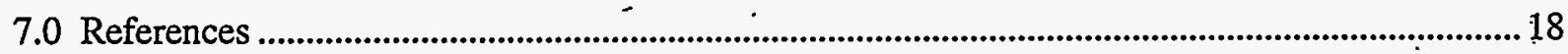

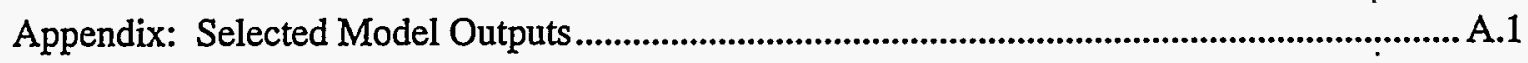




\subsection{Introduction}

The Western Area Power Administration (Western) markets and transmits electric power throughout 15 western states. Western's Sierra Nevada Customer Service Region (Sierra Nevada Region) markets approximately 1,480 megawatts (MW) of firm power (and $100 \mathrm{MW}$ of seasonal peaking capacity) from the Central Valley Project (CVP) and other sources and markets available nonfirm power from the Washoe Project.

Western's mission is to sell and deliver electricity generated from CVP powerplants. The hydroelectric facilities of the CVP are operated by the Bureau of Reclamation (Reclamation). Reclamation manages and releases water in accordance with the various acts authorizing specific projects and with enabling legislation. Western's capacity and energy sales must be in conformance with the laws that govern its sale of electrical power. Further; Western's hydropower operations at each facility must comply with minimum and maximum flows and other constraints set by Reclamation, the U.S. Fish and Wildlife Service, or other agencies, acting in accord with law or policy.

Existing contracts for the sale of the Sierra Nevada Region's resources expire in the year 2004. The efforts involved with renewing these contracts involve determining levels of long-term firm power resources to be marketed and subsequently entering into contracts for the delivery of related products and services. The results of these efforts could involve major Federal actions with potentially significant impacts to the environment. Consequently, a 2004 Power Marketing Environmental Impact Statement (2004 EIS) is being prepared in compliance with the National Environmental Policy Act of 1969 (NEPA), as amended (Western 1996).

In developing alternatives for the 2004 EIS, the Sierra Nevada Region focused on several component groups - key elements of the marketing program - that vary across the alternatives. The Sierra Nevada Region's intent in establishing the ranges for the variable components was to use a "tent stakes" . approach in constructing alternatives. Using this approach, the alternatives were designed to encompass the range of reasonable options; thus, the analyses of their environmental effects would bracket the range of potential impacts. Although the final marketing plan is not likely to be identical with any one of the 2004 EIS alternatives, it will fall within the range of the impacts assessed. If no significant impacts to a specific aspect of the environment can be found between the alternatives, it can safely be assumed that the Sierra Nevada Region's operation will have no impact on that specific aspect of the environment.

The three alternatives that encompass the range of reasonable options are the following:

- No Action refers to a continuation of Sierra Nevada Region's current approach to marketing within expected operating constraints. Currently, Sierra Nevada Region's hydropower facilities are operated close to maximum peaking.

- Peaking Operations (i.e., the peaking alternative) refers to storing and releasing water from hydroelectric facilities to generate electricity in a relatively short period of time to meet maximum 'demand requirements. This approach would emphasize periodic water releases from dams above regulating reservoirs timed to produce electricity when it is most needed. In the peaking alternative, 
the pool elevations within the regulating reservoirs will fluctuate to the maximum allowed within the established constraints. Pool elevations will span the full range between full pool and minimum operating pool on a weekly or daily basis. This alternative is quite close to the no-action alternative.

- Baseload Operations (i.e., the baseload alternative) refers to releasing water from hydroelectric facilities to generate electricity at a relatively constant rate. This approach would emphasize a steady water release rate from the major storage reservoirs. Since the regulating reservoirs would not be required to fluctuate their pool elevation in order to maintain nearly steady releases, the pools in the regulating reservoirs would be held steady at full pool.

Water temperature and water flow rates have been identified as critical parameters in the habitat suitabil- . ity for many fish, including some species listed as threatened or endangered.. Howeyer, the flow rates below the regulating reservoirs are the same for all alternatives. Therefore, the assessment of impacts from water changes was limited to temperature changes that may occur downstream of the regulating reservoirs based on the differences in the three alternatives. Thermal calculations were designed to detect any changes in the temperature of releases from the regulating reservoirs.

This document describes the analysis methodology and results of an assessment of the magnitude of the change in water temperature that may result due to Sierra Nevada Region's implementation of any of these alternatives. A brief description of the CVP, including the environment and the hydrosystem, is presented in the following sections. In subsequent sections, a thorough description is presented of the water temperature analysis methodology and results. 


\subsection{Geography and Topography of the Central Valley Project}

The CVP is a large water control and delivery system, initially authorized by Congress in 1935 , which covers approximately one-third of the State of California. The water control system consists of storage reservoirs that provide seasonal and annual flow regulation, smaller regulating reservoirs for diversion of water and smoothing of upstream dam and powerplant releases, and canals and pumping plants for the delivery of project water. The CVP is located within the Central Valley and Trinity River basins of California.

\subsection{The Central Valley Basin}

The Central Valley Basin of California extends 500 miles in a northwest-to-southeast direction, with an average width of about 120 miles. The basin is surrounded by mountains except for a single outlet to the west at the Carquinez Strait. The Central Valley floor occupies about one-third of the basin, is about 400 miles in length, and averages 50 miles in width. The Cascade and Sierra Nevada ranges on the north and east rise in elevation to $14,000 \mathrm{ft}$ and the Coast Range on the west to as high as $8,000 \mathrm{ft}$. Two major river systems exist in the basin: the Sacramento River system in the north and the San Joaquin in the south. The two river systems join at the Sacramento-San Joaquin Delta (the Delta) where the waters commingle before emerging through the Carquinez Strait into San Francisco Bay.

The climate of the Central Valley is characterized as Mediterranean, with long, warm, dry summers that provide ideal growing conditions for a wide variety of crops under irrigation. The winters are cool and moist. Severe cold weather does not occur, but the temperatures drop below freezing occasionally in virtually all parts of the valley. Rainfall decreases from north to south, with precipitation levels much greater in the mountain ranges surrounding the valley. The average annual rainfall of the Central Valley ranges from about 5 inches in the south to 30 inches in the north. About 80 inches of precipitation, much of it in the form of snow, occur annually at higher elevations in the northern ranges and about 35 inches occur in the southern mountains. About $85 \%$ of the precipitation falls from November through April. Therefore, large variations in runoff exist throughout the year, with larger flows occurring during winter ard spring and lesser flows during the summer and fall.

The Sacramento River Basin and the San Joaquin River Basin, which are within the Central Valley Basin, reach a common confluence at the Delta. Because the basins are operated as a system, the actions in one basin have the potential to impact water quantity and quality; habitat for fish and wildlife; and aesthetic, recreational, and socioeconomic values of the other. These basins and the Delta are described below.

The Sacramento River Basin includes the west drainage of the Sierra Nevada and Cascade ranges, the easterly drainage of the Coast Range, and the valley floor. The basin covers about 26,500 square miles and extends from north of Lake Shasta to Lakes Folsom and Natoma. Major tributaries to the basin include the Sacramento, Feather, Yuba, and American rivers. The greatest volume of runoff is generated by melting Sierra snowpack occurring in early spring and summer. In years of normal runoff, the Sacramento River Basin contributes about $70 \%$ of the total runoff to the Delta. 
The San Joaquin River Basin encompasses more than 11,000 square miles between the crest of the Sierra Nevada Range and the crest of the Coast Range and stretches to the divide between the San Joaquin and Kings rivers. Major tributaries in the basin are the San Joaquin, Merced, Tuolumne; and Stanislaus rivers. During normal runoff years, the San Joaquin contributes about $15 \%$ of the total runoff to the Delta. Water is imported.into the San Joaquin River Basin through the Delta-Mendota Canal of the CVP. Major water exports are through the Friant-Kern Canal and the Hetch Hetchy Aqueduct. During the irrigation season and in January and February, much of the San Joaquin River Basin flow is made up of agricultural drainage and local surface runoff.

\subsection{The Trinity, Basin}

The Trinity River Basin drains approximately 3,000 square miles in northwestern California before flows join with the Klamath River and drain into the Pacific Ocean. The mountainous terrain of the Trinity Basin ranges in elevation from above $9,000 \mathrm{ft}$ to $300 \mathrm{ft}$ at the town of Weitchpec where the Trinity River joins the Klamath River. The average runoff in the Trinity is approximately $1,200,000$ acre-ft at Lewiston and 3,800,000 acre-ft at Weitchpec. The Trinity River Basin exports water at Lewiston Dam to the Sacramento River Basin via the Clear Creek Tunnel. 


\subsection{Hydrosystem of the Central Valley Project}

The CVP includes 12 dams and reservoirs with a total storage capacity of 10:66 million acre-ft (MAF). Water released from the CVP dams is controlled by regulating reservoirs situated downstream. These regulating reservoirs were designed to accept variable levels of water released from the main storage reservoirs and to maintain nonfluctuating flows downstream. In this way, water-level fluctuation is confined to the regulating reservoirs. Power operations do not control the timing or quantities of water released from the regulating reservoirs.

Sierra Nevada Region's actions are limited to specific hydropower generators and the regulating reservoirs that maintain nonfluctuating flows downstream from those facilities. These regulating reservoirs include Lewiston, Keswick, Lake Natoma, and Tulloch. The Sierra Nevada Region has no discretion over how water is released from the regulating reservoirs. At the generating facilities upstream of the regulating reservoirs, the Sierra Nevada Region has discretion in the hourly release of water and cannot operate generation in a manner that would change regulating reservoir releases. Therefore, within the CVP, the environment that may be affected by the alternatives described in this 2004 EIS is limited to the regulating reservoirs. The main storage reservoirs are substantially larger than the regulating reservoirs, and changes in power operations do not create noticeable fluctuations in their surface elevations on a daily basis. The characteristics of each of the four regulating reservoirs are discussed below.

\subsection{Lewiston Reservoir}

Lewiston Reservoir is located within the Trinity River Basin. The Trinity River hydrosystem was developed to provide power, flood control, and transbasin diversion of Trinity River water to the Sacramento River to augment the supply of water in the CVP. Water is stored in Clair Engle Lake, behind Trinity Dam. Downstream of Clair Engle Lake, water is regulated at Lewiston Dam and either diverted through Clear Creek Tunnel into the Sacramento River Basin or released to the Trinity River. Water diverted through Clear Creek Tunnel flows into Whiskeytown Reservoir behind Whiskeytown Dam on Clear Creek, a tributary of the Sacramento River. Water then flows through either Spring Creek Tunnel into Keswick Reservoir on the Sacramento River or through Whiskeytown Dam into Clear.Creek, which enters the Sacramento River downstream of Keswick Reservoir. Sierra Nevada Region has limited operating discretion at Trinity, Carr, and Spring Creek powerplants to shape water releases on a hourly basis. Mean annual inflow from Trinity River to Clair Engle Lake is 1.2 MAF.

Lewiston Dam, completed in 1963, is located on the Trinity River, 7 miles downstream from Trinity Dam. Lewiston Reservoir functions as a regulating reservoir to eliminate flow fluctuations downstream for Trinity Powerplant and as a forebay to Carr Powerplant. The reservoir also supplies water to the California Department of Fish and Game (CDFG) and Lewiston hatchery. Releases to the Trinity River and diversions to the Sacramento River Basin are controlled at Lewiston Dam. Lewiston Reservoir has a total capacity of 14,660 acre-ft, with 2,890 acre-ft of active storage. 


\subsection{Keswick Reservoir}

Keswick Reservoir is located within the upper Sacramento River Basin. Shasta Dam and lake on the Sacramento River were developed primarily to provide flood control, storage of winter runoff for downstream irrigation in the Sacramento and San Joaquin valleys. Other primary functions are maintenance of navigational flows, conservation of fish in the Sacramento River, protection of the Bay/Delta from salt water intrusion, municipal and industrial water, and generation of power. The drainage area of the Sacramento River above Shasta Dam encompasses 6,665 square miles. The Sierra Nevada Region has limited operating discretion to release water on an hourly basis at Shasta Powerplant.

Keswick Dam, completed in 1950, is located approximately 8 miles downstream of Shasta Dam. (Shasta Lake has a total storage capacity of 4.5 MAF of which 3.96 MAF is active storage.) Keswick is a regulating reservoir for Shasta Lake and Trinity River diversions, eliminating flow fluctuations from the upstream dams and powerplants. The reservoir has a total storage capacity of 23 TAF with 7.5 TAF of active storage.

\subsection{Lake Natoma}

The American River drainage basin encompasses 1,877 square miles and, at its confluence with the Sacramento River, contributes approximately $15 \%$ of total Sacramento River flow. The American River enters the Sacramento River at the city of Sacramento. The major unit of the American River Division is the Folsom Unit, located on the Amierican River, which includes Folsom Dam, lake, and powerplant; Nimbus Dam and powerplant; and Lake Natoma. Nimbus Dam, completed in 1955, is located on the American River, 7 miles belów Folsom Dam. Nimbus Dam backs up Lake Natoma, eliminating flow fluctuations from Folsom Powerplant.

\subsection{Tulloch Reservoir}

New Melones Dam, built by the U.S. Army Corps of Engineers in 1979, is located on the Stanislaus River, 60 miles upstream of the confluence with the San Joaquin River. New Melones Lake has a total storage capacity of 2.4 MAF, of which 2.1 MAF is active storage. Mean annual inflow to New Melones Lake is approximately 1.1 MAF. Although not part of the CVP, Tulloch Reservoir, downstream of the New Melones Dam; regulates water releases from New Melones Dam. Tulloch Reservoir has a total storage capacity of 68.4 TAF, of which $10 \mathrm{TAF}$ is used for nullifying fluctuations in water releases from New Melones. Tulloch Reservoir is owned and operated by the Oakdale and South San Joaquin Irrigation Districts. 


\subsection{Water Temperature Model}

Water temperature has been identified as a critical parameter of habitat suitability for many fish, including some species listed as threatened or endangered, such as winter-run Chinook salmon in the Sacramento River. Reclamation is attempting to meet seasonal water temperature criteria to benefit fish in downstream reaches through storage reservoir releases. Water release temperatures are a function of seasonal and daily climatic conditions, withdrawal level from primary storage reservoirs, surface area of reservoirs, and flow rates within the reservoirs and rivers. Sierra Nevada Region's power generation will not change the seasonal operation of the main storage projects (Trinity, Shasta, Folsom, and New Melones). Also, the hourly flow rates below the regulating reservoirs are the same for all alternatives. Therefore, assessment of water impacts was limited to changes in temperatures that may occur downstream of the regulating reservoirs (Lewiston, Keswick, Natoma, and Tulloch) related to differences in hourly release schedules associated with the three hydropower alternatives. Thermal calculations were designed to detect changes in the temperature of releases from the regulating reservoirs.

In this section, the approach employed in the analysis is discussed, including the numerical implementation of the model as an Excel spreadsheet and the input, output, and limitations of the model.

\subsection{Approach}

The unique conditions of regulating reservoirs (generally well mixed with very short residence times) required the development of a new reservoir thermal model. Most of the existing reservoir thermal models were developed to consider temperature changes occurring over longer time scales than are appropriate for many regulating reservoirs (Smith 1978). Regulating reservoirs generally have thermal behavior similar to deep, slow moving rivers as opposed to storage reservoirs. The model was implemented as a linked set of Microsoft Excel workbooks. It uses a one-dimensional Lagrangian approach to represent the water movement and considers all of the important surface heat exchange processes (shortwave solar radiation, long-wave atmospheric radiation, reflected short-wave and long-wave radiation, back radiation, evaporation, and conduction) on an hourly basis. The predictive reliability of the model is limited by the lack of site-specific climate data and, in certain situations, the assumption of unstratified flow.

\subsubsection{Lagrangian Transport}

Most reservoir thermal models employ an Eulerian scheme to represent the thermal and flow processes. Eulerian approaches allow the analyst to understand the spatial and temporal distribution of water and energy in the reservoir for the entire domain. Eulerian schemes tend to suffer from numerical dispersion and are generally computationally intensive and conditionally stable. In order to assess the thermal impacts of hourly release patterns, running the model at time steps considerably less than 1 hour would be required to ensure computational stability. Eulerian schemes remain the preferred method for reservoirs with relatively long residence times. The Lagrangian approach is an alternative to Eulerian schemes that is well suited for reservoirs with shorter residence times. 
A Lagrangian scheme follows individual parcels through a domain. Each parcel is assumed to not interact with other parcels. This scheme is computationally efficient and unconditionally stable. The residence time of each parcel leaving the regulating reservoir each hour can be estimated from the assumed inflows and outflows and the calculated reservoir contents. The surface energy flux for each of the hours from the time the parcel enters the reservoir to the time the parcel leaves the reservoir is used to compute the net energy flux and temperature change.

\subsubsection{Surface Heat Exchange}

Each of the various processes by which heat is exchanged between the water bodies and the atmosphere have been thoroughly studied. Short-wave solar radiation, long-wave atmospheric radiation, long-wave back-radiation, evaporation, condensation, reflected solar radiation, reflected atmospheric radiation, and conduction are components of the total water surface heat exchange.

Figure A.1 in the appendix shows hourly estimates for each of the components of the surface heat exchange budget estimated for Keswick Reservoir on September 2, 1990. Details of the methods used to estimate each component are discussed in the following sections.

\section{Short-wave Solar Radiation}

Potential solar radiation is the maximum radiation that would reach the earth's surface if there was no atmospheric attenuation. The instantaneous potential solar radiation for a horizontal surface is given by:

$$
S^{\circ}=S^{\prime}\left(\frac{\bar{d}}{d}\right)^{2} \sin a
$$

where $S^{\prime}$ is the solar constant $\left(-1360 \mathrm{~W} / \mathrm{m}^{2}\right)$, d is the current earth-sun distance, $\bar{d}$ is the average earthsun distance, and $a$ is the altitude of the sun above the horizon. Changes in the earth-sun distance leads to variation of the extraterrestrial radiation flux in the range of $+/-3 \%$. The dependence of extraterrestrial radiation on the Julian day $(n)$ is given by (Duffie and Beckman 1974):

$$
\left(\frac{\bar{d}}{d}\right)^{2}=\left(1+0.033 \cos \left[\frac{360 n}{365}\right]\right)
$$

The solar altitude in $a$ is calculated as

$$
\sin a=\sin \phi \sin \delta+\cos \phi \cos \delta \cos h
$$

where $\phi$ is the site latitude, $\delta$ is the declination of the sun, and $h$ is the hour angle of the sun. The solar declination is given in radians by: 
$\delta=23.45 \frac{\pi}{180} \sin \left(2 \pi\left[\frac{284+n}{365}\right]\right)$

The hour angle $(h)$ is the angular displacement of the sun east or west of the local meridian due to a rotation of the earth's axis at $2 \pi$ radians per 24 hours. To determine $h$, local time is first converted to solar time $\left(T_{s}\right)$ :

$T_{s}=$ local time $+\frac{12}{\pi}\left(L_{s t}-L_{l o c}\right)+E$

where $L_{s t}$ is the standard meridian for the local time zone (120 $\pi / 180$ radians $W$ for Pacific Time) and. $L_{l o c}$ is the site longitude in degrees west. The equation of time, $E$, is given by (Duffie and Beckman 1974):

$E=(9.87 \sin 2 B-7.53 \cos B-1.5 \sin B) / 60$

with $B=\frac{2 \pi(n-81)}{364}$. The hour angle in radians from solar noon is calculated as:

$h=\frac{\pi}{12}\left(T_{s}-12\right)$

The actual solar radiation reaching the water body is limited by the cloud cover. Hourly values of cloud cover are obtained from the climate record.

\section{Long-Wave Atmospheric Radiation}

Atmospheric radiation is a function of ambient air temperature and humidity. It constitutes the major thermal loading at night and on cloudy days. Atmospheric radiation is estimated by an empirical formula called "Brunt's formula" (Edinger et al. 1974). The formula expresses the atmospheric radiation $H_{a}$ as:

$H_{a}=4.4 \cdot 10^{-8}\left(T_{a}+273\right)^{4}\left[C a+0.031 \sqrt{e_{a}}\right]$

where

$T_{a}=$ ambient air temperature (C)

$C_{a}=$ Brunt's coefficient

$e_{a}=$ air vapor pressure (mmHg).

Brunt's coefficient is estimated from a table as a function of observed hourly air temperature and cloud cover. 


\section{Reflected Solar Radiation}

The fraction of solar radiation reflected from the water's surface can be estimated using reflectivity ratios. Solar reflectivity is a function of the sun's altitude and of cloud cover. Lookup tables included in the model are based on published tables (Marciano and Harbeck 1952).

\section{Reflected Atmospheric Radiation}

The fraction of atmospheric radiation reflected from the water's surface can also be estimated using a reflectivity ratios. In contrast to solar reflectivity, atmospheric reflectivity is approximately constant (0.03).

\section{Back Radiation}

Water sends energy back to the atmosphere as long-wave radiation. Back radiation is generally the largest single energy loss from water bodies. Water radiates as an almost perfect black body. Therefore, according to the Stephan-Boltzman fourth-power radiation law, $H_{b}\left(\mathrm{~W} / \mathrm{m}^{2}\right)$, the back-radiation can be expressed as:

$$
H_{b}=\varepsilon \sigma^{*}\left(T_{s}+T_{2}\right)^{4}
$$

where

$\varepsilon=$ emissivity of water $(=0.97)$

$\sigma^{*}=$ Stephan-Boltzman constant $\left(5.6710^{-8} \mathrm{~W} \mathrm{~m}^{-2} \mathrm{~K}^{-4}\right)$

$T_{s}=$ water surface temperature (C).

$T_{z}=$ correction for absolute zero $(=273.15)$.

\section{Evaporation}

Heat is transferred from a water'body to the atmosphere through evaporation occurring at the water surface. Each kilogram of water that evaporates also carries away its latent heat of vaporization $\left(2.4510^{6}\right.$ J). An equivalent amount of energy is gained from each kilogram of water condensing at the water surface. Generally, evaporation exceeds condensation. Heat gain due to condensation was not included in this analysis (Edinger et al. 1974).

The heat transferred to the water body can be expressed as:

$$
H_{e}=\beta f(W)\left(T_{s}-T_{d}\right)
$$

where

$T_{d}=$ dew point temperature

$T_{d} \approx\left(14.55+0.114 T_{a}\right) x+\left[\left(2.5+0.007 T_{a}\right) x\right]^{3}+\left(15.9+0.117 T_{a}\right) x^{14}$

$x=1.0-r / 100$. 
$r=$ relative humidity $(\%)$

$f(W)=9.2+0.46 W^{2}$

$W=$ wind speed $(\mathrm{m} / \mathrm{s})$

$\beta=0.35+0.015 T_{m}+0.012 T_{m}^{2}$

$T_{m}=\left(T_{s}+T_{d}\right) / 2$

\section{Heat Conduction .}

Heat can enter or leave the water via conduction. If the air temperature exceeds the water temperature, heat enters the water. If the air temperature is less than the water temperature, heat enters the atmosphere. The rate at which heat is conducted between the water and atmosphere can be expressed as:

$H_{c}=0 . \ddot{4} f(W)\left(T_{s}-\dot{T}_{a}\right)$

\subsection{Implementation}

The model was implemented as a linked set of Excel Workbooks using Microsoft Excel for Windows 95 Version 7.0. Each Workbook is composed of numerous worksheets. The primary role of the WaterBalance.xls workbook is to

- store hourly reservoir inflow and outflow developed for each alternative and each regulating reservoir as part of the PROSYM analysis (Western 1995)

- compute the hourly contents and surface areas for each alternative and each reservoir.

The primary role of the HeatBalance.xls workbook is to

- estimate the hourly surface energy flux based on reservoir location and climate data .

- compute temperature changes for each of the alternatives

- plot the temperature change data for the selected month.

The Sacramento.xls and Redding.xls workbooks contain the hourly climate data for 1987 through 1993. However, prospective users should be warned that due to the massive size of many of the data arrays (e.g., hourly flow values for two different years for four different reservoirs and three different alternatives), the model requires over 50 megabytes of disk space. .

The function of the main worksheets within the HeatBalance.xls and WaterBalance.xls is provided below. 
Table 1. Function of Main Worksheets in HeatExchange.xls

\begin{tabular}{|l|l|}
\hline \multicolumn{1}{|c|}{ Worksheet Name } & \multicolumn{1}{c|}{ Function } \\
\hline Solar Radiation & Performs calculations to estimate short-wave radiation. \\
\hline Parameters & $\begin{array}{l}\text { Contains reservoir location and elevation data and possible problem } \\
\text { configurations. }\end{array}$ \\
\hline Functions & $\begin{array}{l}\text { Visual Basic Macro Functions used to perform many of the } \\
\text { mathematical calculations and interpolations. }\end{array}$ \\
\hline Delta-Temp Chart & $\begin{array}{l}\text { Plot of differences in 3-day mean release temperatures between the } \\
\text { various combinations of alternatives. }\end{array}$ \\
\hline Delta-Temperature & $\begin{array}{l}\text { Performs calculations to estimate the 3-day mean release } \\
\text { temperatures for each of the various alternatives. }\end{array}$ \\
\hline Temperature Chart & Plot of 3-day mean release temperatures for the various alternatives. \\
\hline Temperature & $\begin{array}{l}\text { Performs calculations to estimate the various 3-day mean release } \\
\text { temperature }\end{array}$ \\
\hline Heat Exchange & $\begin{array}{l}\text { Performs calculations of each of the components of the surface } \\
\text { energy budget. }\end{array}$ \\
\hline Climate & $\begin{array}{l}\text { Stores hourly climate data extracted from either Sacramento.xls or } \\
\text { Redding.xls for the specified year and month. }\end{array}$ \\
\hline Surface Energy Balance & $\begin{array}{l}\text { Chart showing the surface energy budget for the first day of the } \\
\text { selected month. }\end{array}$ \\
\hline
\end{tabular}

Table 2. Function of Main Worksheets in WaterBalance.xls.

\begin{tabular}{|l|l|}
\hline \multicolumn{1}{|c|}{ Worksheet Name } & \multicolumn{1}{|c|}{ Function } \\
\hline $\begin{array}{l}\text { Flowsdn, Flowsd1, } \\
\text { Flowsdb, Flowsab, } \\
\text { Flowsan, Flowsa1 }\end{array}$ & $\begin{array}{l}\text { Raw inflow/outflow data from PROSYM analysis. FlowsXY where } \\
X \text { refers to dry/critical water year (d) or average water year (a) and } \\
\text { where } Y \text { refers to no action (n), baseload (b), or peaking (1) } \\
\text { alternatives. }\end{array}$ \\
\hline $\begin{array}{l}\text { Lewiston, Keswick, } \\
\text { Natoma, Tulloch }\end{array}$ & $\begin{array}{l}\text { Calculates the residence times and normalized depths for each hour } \\
\text { of each year (average and critical) for each alternative. }\end{array}$ \\
\hline $\begin{array}{l}\text { Lewiston Stage Storage, } \\
\text { Keswick Stage Storage, } \\
\text { Natoma Stage Storage, } \\
\text { Tulloch Stage Storage }\end{array}$ & $\begin{array}{l}\text { Raw stage storage data obtained from Reclamation for each } \\
\text { reservoir. }\end{array}$ \\
\hline $\begin{array}{l}\text { Checks and Balances } \\
\text { Calculates maximum reservoir drawdowns to ensure the } \\
\text { inflow/outflow patters are feasible and consistent with } \\
\text { Reclamation's reservoir operating guidelines. }\end{array}$ \\
\hline $\begin{array}{l}\text { Pool Elevation } \\
\text { Calculates the pool elevation for each hour of year for each } \\
\text { alternative for each reservoir. }\end{array}$ \\
\hline $\begin{array}{l}\text { Unsorted Normalized } \\
\text { Storage }\end{array}$ & $\begin{array}{l}\text { Calculates the relative reservoir contents relative to full pool based } \\
\text { raw flow data. }\end{array}$ \\
\hline
\end{tabular}




\subsection{Input}

The model requires information on the climate, inflows/outflows, and reservoir characteristics. Each of the input data sets are discussed in the following sections.

\subsubsection{Climate}

Hourly climate data are available from the National Climate Data Cénter (NCDC) for selected stations. These data are generally of very high quality and are available from NCDC and private data distributors. The NCDC TD-3280 data sets include numerous climate parameters. For this analysis, the following data fields are used:

- windspeed (knots)

- relative humidity (\%)

- sky cover (\%)

- dry bulb temperature $\left({ }^{\circ} \mathrm{F}\right)$.

These data sets also provide dew point temperature data; however, the model estimates the dew point temperature from the relative humidity and dry bulb temperature using an empirical relationship.

Unfortunately, no long-term hourly climate data are available right at the reservoir locations. Redding.xls and Sacramento.xls contain data from the Redding and Sacramento airports, respectively. The Redding airport is reasonably close to Keswick Reservoir. This is also the closest long-term hourly data set for Lewiston Reservoir, which is over 25 miles away and at a much higher elevation than the Redding airport. The Sacramento airport is reasonably close to Lake Natoma. This data set is also used for Tulloch Reservoir, which is nearly 50 miles away.

\subsubsection{Flows}

Hourly inflows and weekly outflows where developed for each alternative in a separate study performed by R.W. Beck, Inc (Western 1995). The outflows are assumed steady for an entire month and do not change between alternatives. In the baseload alternative, the inflows to the regulating reservoir are also steady for the entire month. However, in the no-action and peaking alternatives, the inflows change hourly. These changing inflows and steady outflow result in the pool elevations fluctuating during the month. These changes result in different hourly storage volumes and different hourly surface area available for surface heat exchange.

\subsubsection{Reservoir Characteristics}

Reservoir stage-capacity data were obtained from Reclamation for each of the four regulating reservoirs. These data are included in the WaterBalance.xls workbook. In order to calculate the solar energy flux, it was necessary to know the latitude of the reservoirs. The latitude and longitude for each of the reservoirs are included in the Parameters worksheet in the HeatBalance.xls workbook. 


\subsection{Model Output}

Output from the model is available in a variety of figures (Excel charts) and tables (Excel worksheets). Figures and tables are available for surface energy fluxes, gain in water temperature, and differences in water temperature gain between alternatives. The most important model outputs are discussed below.

\subsubsection{Hourly Energy Fluxes}

Tables and figures of estimated hourly energy fluxes are provided by the model for the selected month. The tables and figures are provided in the Heat Exchange and Surface Energy Balance worksheets, respectively, in the HeatBalance.xls workbook. The figure only shows the energy budget for the first day of the month. Figure A.1 in the appendix show the estimates of each of the heat transfer process components for Lake Natoma using hourly climate data from Sacramento Airport September 2, 1990. The reservoir inflow temperature was assumed to be $50^{\circ} \mathrm{F}$.

\subsubsection{Release Temperatures}

Estimated release temperature gains (relative to inflow temperature) for each hour of the selected week are also available as either figures or tables. The tables and figures are provided in the Temperature and Temperature Chart worksheets, respectively, in the HeatBalance.xls workbook. Figure A.2 show these data. Due to the Lagrangian approach employed, not all hours have temperature estimates, in such cases, a \#VALUE!-occurs in the spreadsheet and the value is plotted as 0 on the chart. Such results are not errors. In the figures and tables in the workbook BA refers to the baseload alternative for an average water year, PA refers to the peaking alternative for an average water year, NA refers to the no-action alternative for an average water year, BC refers to the baseload alternative for a critical (adverse) water year, PC refers to the peaking alternative for a critical (adverse) water year, and NC refers to the noaction alternative for a critical (adverse) water year.

\subsubsection{Temperature Difference}

Estimated release temperature gain differences between alternatives are also available às either figures or tables. The tables and figures are provided in the Delta-temperature and Delta-temperature Chart worksheets, respectively, in the HeatBalance.xls workbook. "Delta" in this instance does not refer to the Delta region of the Central Valley Basin but refers to the differences in estimated temperatures between alternatives. Figure A.3 show these data. The delta temperature chart (Figure A.3) shows the difference between the estimated release temperatures for each of the alternatives for both adverse (critical) and average year conditions. 


\subsection{User Interface}

A simple Excel Dialog sheet is provided in the HeatBalance.xls worksheet that allows the user to select the desired climate data site, the year and week of the climate data, inflow temperature, and reservoir. To enter the Dialog sheet, just push the button on the Start Me Up sheet.

\subsection{Limitations}

While the most important processes have been included, the model contains several important limitations. Reservoirs with relatively short residence times generally do not have the time to develop . stratified flow conditions. However, reservoirs such as Tulloch, with relatively long residence times will

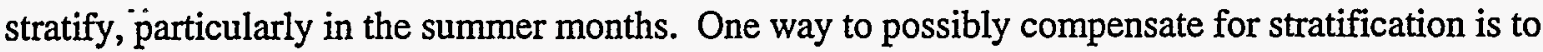
adjust the stage contents relationship to treat the cooler deeper pool as a stable pool (i.e., not included in the "effective" contents).

As mentioned earlier, the lack of available hourly climate data at the regulating reservoirs is a serious limitation to the model's predictive abilities. The model should be used less in a predictive mode than in a comparative mode (i.e., to assess the expected magnitude of the difference between release temperatures for the various alternatives under a variety of climate conditions). 


\subsection{Simulation Results}

Figure A.2 shows the change in temperature between the water released for the reservoir and the water entering the reservoir. The impact of the diumal variation in the surface heat balance is clearly seen for the week considered (September 2-8, 1990). (Since the PROSYM modeled flow data are not consistent with the actual flow data occurring at this period, these results should not be used for calibration or verification purposes.) From the conservative assumptions of the model, it can reasonably be assumed that the model will likely overestimate the change in release temperature.

The difference between the alternatives must be compared to assess the impact of any change in Sierra Nevada Region's operations. Comparisons should be made separately for both the average and the adverse year conditions. Comparing release temperatures from peaking operation under adverse water year conditions, for instance, with release temperatures from peaking operation under average water year conditions says nothing about the impact of hydrosystem operation, since hydrosystem operation does not impact the climate.

Figure A.3 shows the difference between alternatives. Distinguishing any temporal trends from the delta temperature chart is difficult. The magnitude of the change in temperature between alternatives is the most important aspect. It appears from this plot that the baseload alternative would result in slightly higher release temperatures. Using a 1-day moving average filter (Figure A.4), the change is generally less than $1.0^{\circ} \mathrm{F}$. When this $1.0^{\circ} \mathrm{F}$ change is compared to the release temperature change (approximately $10^{\circ} \mathrm{F}$, see Figure A.2), the difference between alternatives is considered negligible. 


\subsection{Conclusions}

The change in the release temperature from the reservoir is nearly proportional to the net energy flux, the surface area, and residence time. It is inversely proportional to the reservoir volume. The residence time . is the average time it takes for water to pass through the reservoir. In storage reservoirs, residence times are defined in terms of months or years; however, in regulating reservoirs, the residence times are typically a few days. Lowering pool elevations reduces the surface area and the residence times. Therefore, over the long term, peaking operations with pool elevations often less than the full stable pool conditions associated with baseload operations would generally result in lower release temperatures. However, dynamic effects associated with peaking operations may result in temperatures being higher for short periods. In either case, the magnitude of the differences between temperature changes is very small. -.

The effects of the regulating reservoir water releases on downstream temperature are so small that, although they can be calculated, they could not be reliably measured in the river. This finding is true for all of the alternatives. Neither fish, recreation, nor temperature criteria violation frequency will be impacted by temperature fluctuations resulting from Sierra Nevada Region's influence on the operation of the hydropower system. 


\subsection{References}

Duffie, J.A., and W.A. Beckman. 1974. Solar Energy Thermal Processes. John Wiley and Sons, New York, NY.

Edinger, J.E., D.K.Guyer, and J.C. Geyer. 1974. Heat Exchange and Transport in the Environment. Electric Power Research Institute, Palo Alto, California.

Marciano, J.J., and G.E. Harbeck. 1952. Mass Transfer Studies in Water Loss Investigations: Lake Hefner Studies. Geologic Survey Circular 229, USGS, Washington, D.C.

Smith, D.J. 1978. Water Quality for River-Reservoir Systems Computer Program Description. U.S. Army Corps of Engineers, Water Support Center, the Hydrologic Engineering Center, Davis, California.

Western Area Power Administration. 1995. Western Area Power Administration 2004 Power Marketing Plan EIS Modeling. Prepared by P.G. Scheurman at R.W. Beck for the Western Area Power Administration, Sacramento, California.

Western Area Power Administration. 1996. 2004 Power Marketing Program Draft Environmental Impact Statement. DOE/EIS-0232, Sierra Nevada Customer Service Region, Folsom, California. 
Appendix

Selected Model Outputs 
Surface Energy Flux

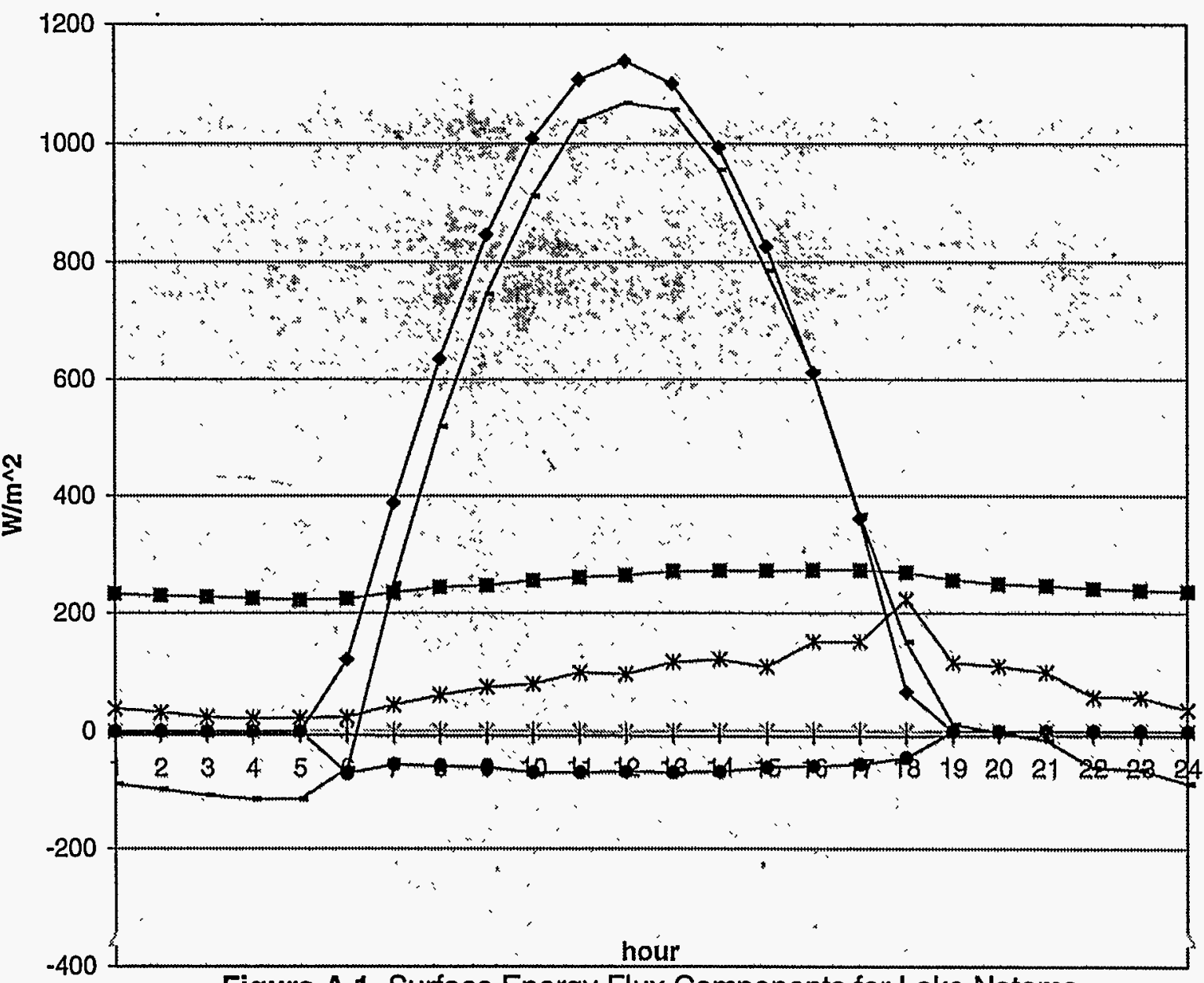

Figure A.1. Surface Energy Flux Components for Lake Natoma Using Climate Data for Aug 26, 1990 $\rightarrow-$ Short Wave Solar Radiation $\rightarrow$ - Long Wave Atmospheric Radiation - 2 - Long Wave Back Radiation $\rightarrow x-$ Evaporation Heat Loss *-Conduction Heat Transfer $\rightarrow-$ Reflected Solar

T-Reflected Atmospheric Radiation -Total 


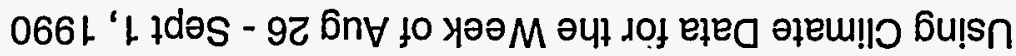

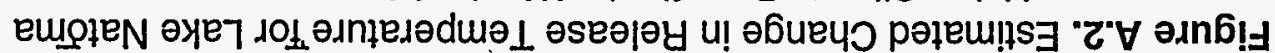

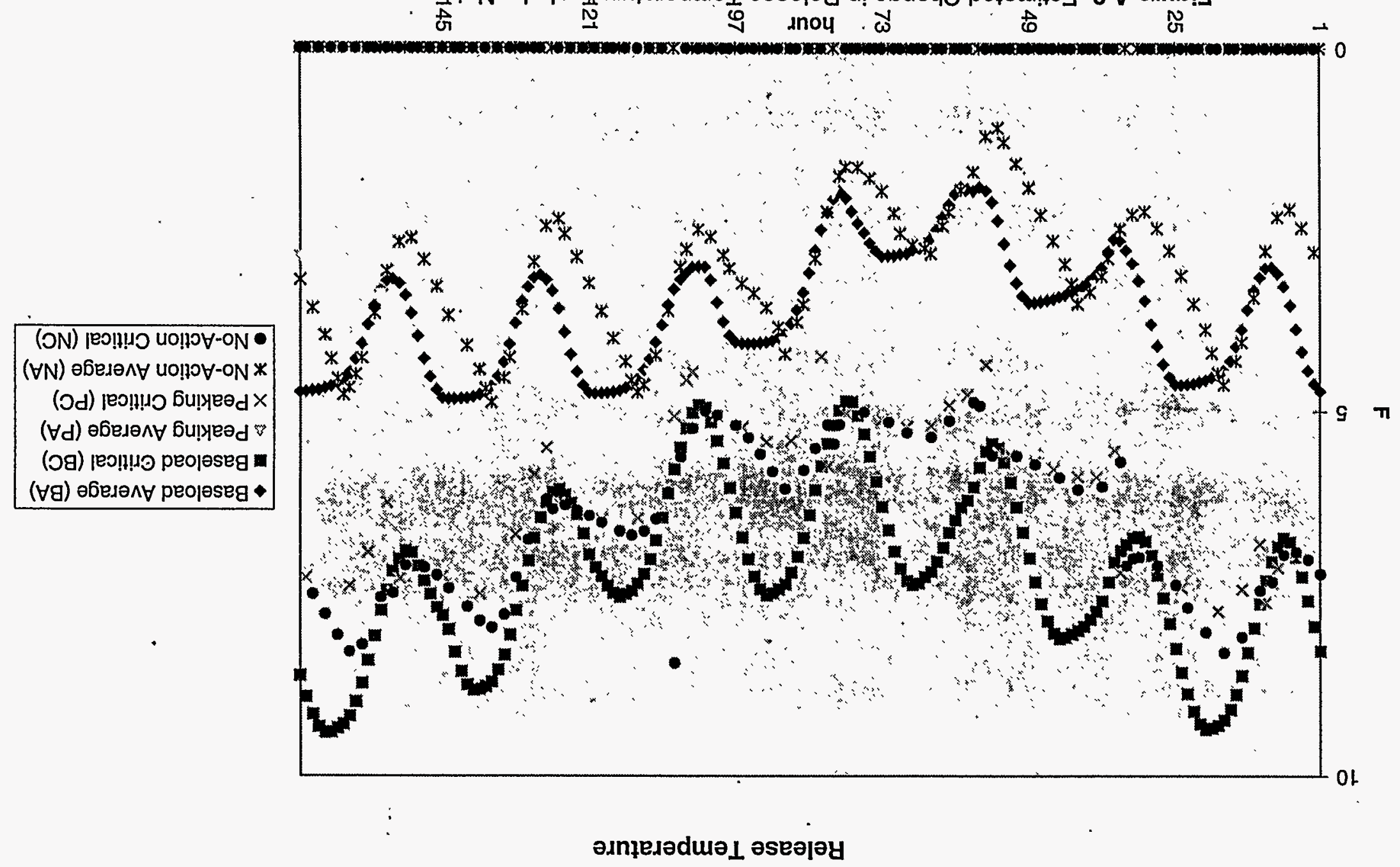




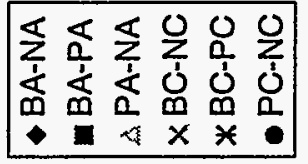

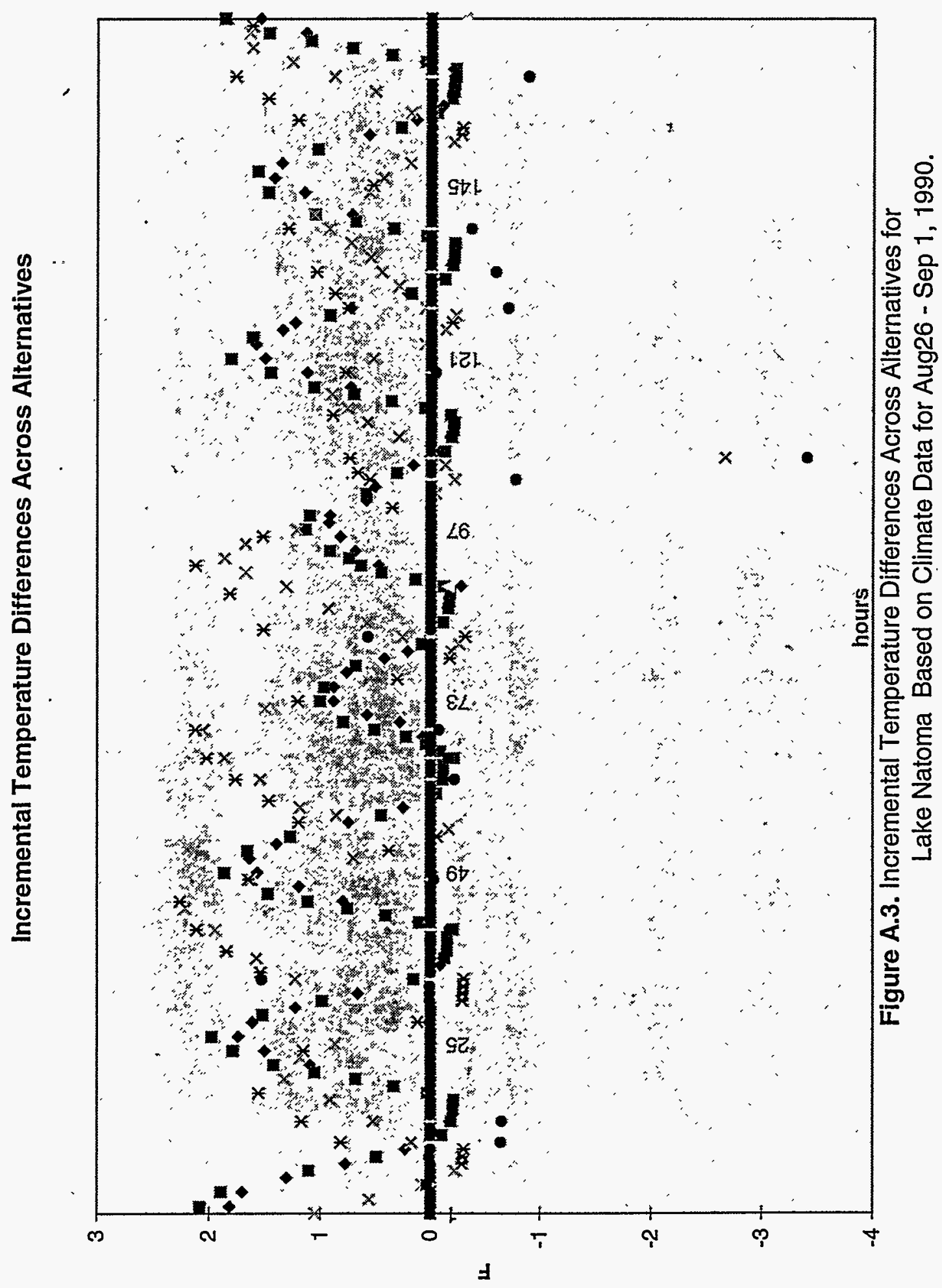




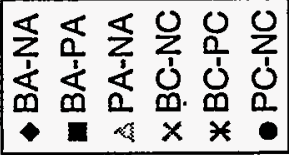

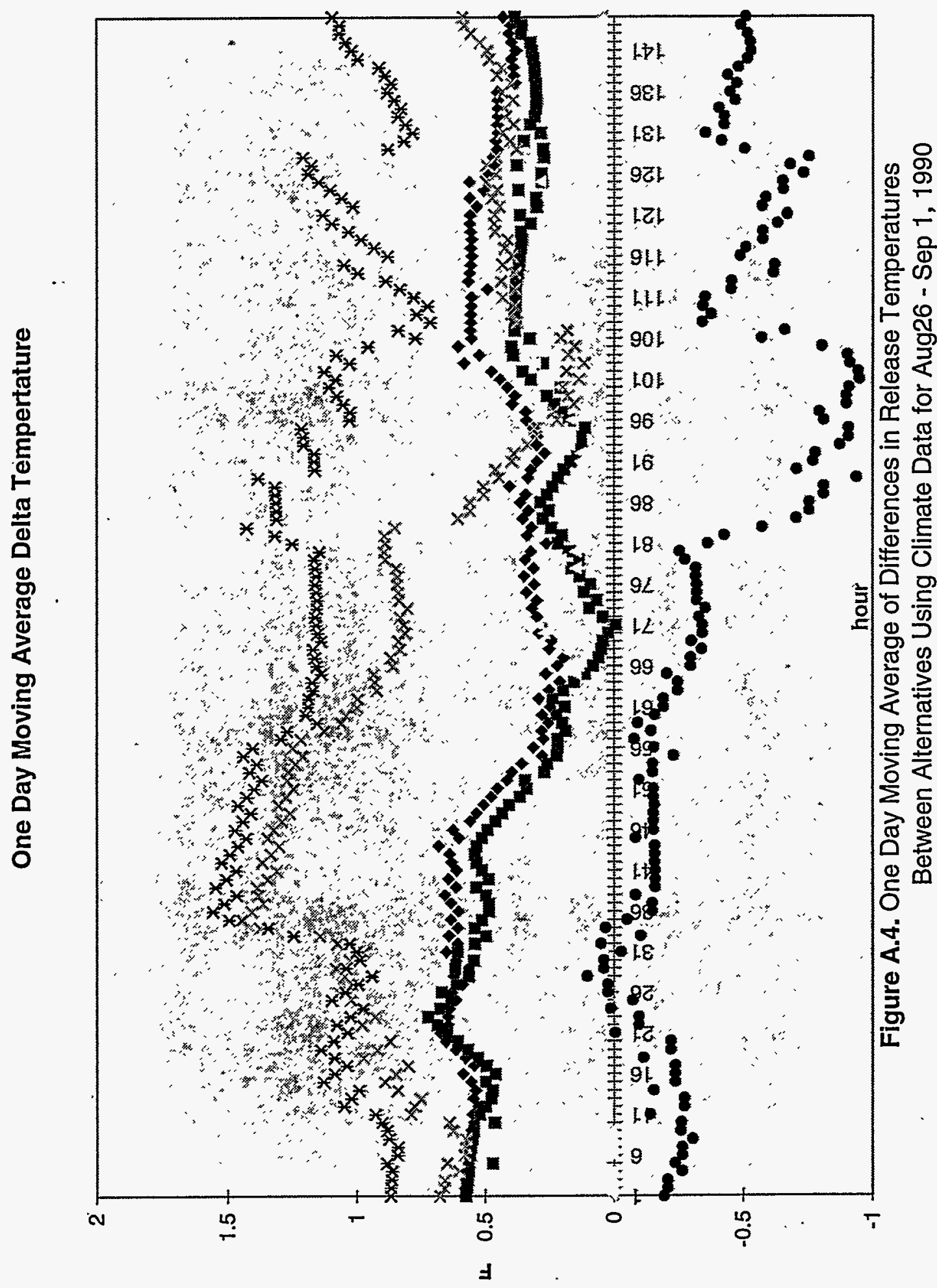

